\begin{tabular}{|c|l|}
\hline Title & $\begin{array}{l}\text { Generation of a - Nitroal kyl Radicals by Oxidation of Nitronate A nions with Cerium(IV) A mmonium Nitrate and Their } \\
\text { A ddition Reaction to Electron-Rich Olefins }\end{array}$ \\
\hline Author(s) & A rai, Noriyoshi; Narasaka, Koichi \\
\hline Citation & $\begin{array}{l}\text { Chemistry Letters, 24(11), 987-988 } \\
\text { https://doi.org/10.1246/1.1995.987 }\end{array}$ \\
\hline Issue Date & 1995 \\
\hline Doc URL & http://hdl.handle.net/2115/70770 \\
\hline Type & article \\
\hline File Information & cl.1995.987.pdf \\
\hline
\end{tabular}

Instructions for use 


\title{
Generation of $\alpha$-Nitroalkyl Radicals by Oxidation of Nitronate Anions with Cerium(IV) Ammonium Nitrate and Their Addition Reaction to Electron-Rich Olefins
}

\author{
Noriyoshi Arai and Koichi Narasaka* \\ Department of Chemistry, Graduate School of Science, The University of Tokyo, 7-3-1, Hongo, Bunkyo-ku, Tokyo 113
}

(Received July 31, 1995)

\begin{abstract}
$\alpha$-Nitroalkyl radicals are generated by oxidation of nitronate anions with cerium(IV) ammonium nitrate. When the reactions are carried out in the presence of electron-rich olefins, such as silyl enol ethers, intermolecular addition of the radicals proceeds to afford $\beta$-nitroketones, which are further converted to $\alpha, \beta$ unsaturated ketones in good yield.
\end{abstract}

Though several attempts have been carried out to form carbon-carbon bonds by the use of carbon-centered radicals generated by the one-electron oxidation of carbanions, most of them afford self-coupling products. ${ }^{1-3}$ Few examples have been developed for the intermolecular carbon-carbon bond forming reactions. ${ }^{4-6}$ In these intermolecular reactions, the yield of the products is not sufficiently high, even with the use of large excess amounts of radical acceptors. We have been investigating the generation of carbon-centered reactive species by oxidation of $\alpha$-stannyl sulfides, ${ }^{7} N$-( $\alpha$-stannylalkyl)amides,${ }^{8}$ or $\alpha$-stannyl esters $^{9}$ with cerium(IV) ammonium nitrate (CAN). In the course of this study, $\alpha$-nitroalkyl radicals were found to be generated by oxidation of nitronate anions with CAN, and intermolecular addition reaction proceeded with electron-rich olefins in high yield. 10,11

When a solution of potassium salt of 1-nitro-4-phenylbutane (1a) in methanol, prepared by treating $1 \mathrm{a}$ with $\mathrm{KOH}$, was added to a solution of CAN and $\alpha$-trimethylsiloxystyrene (2) in methanol at $-78{ }^{\circ} \mathrm{C}(\mathbf{1 a}: \mathrm{KOH}: \mathrm{CAN}: 2=1: 1.3: 1.9: 0.85), 12$ the reaction proceeded smoothly to give 3-nitro-1,6-diphenylhexan-1-one (3) as a crude product. Since purification of the nitroketone 3 by preparative TLC (silica gel) turned out difficult because of the elimination of nitrous acid from 3 , the crude product was purified after converting to 1,6-diphenyl-2-hexen-1one (4). Thus, by treatment of the crude nitroketone 3 with triethylamine, the $\alpha, \beta$-unsaturated ketone 4 was obtained in $95 \%$ yield based on the silyl enol ether 2 , accompanied by the $5 \%$ recovery of $\mathbf{1 a}$ and the formation of self-coupling product 5 (Eq. $1)$.

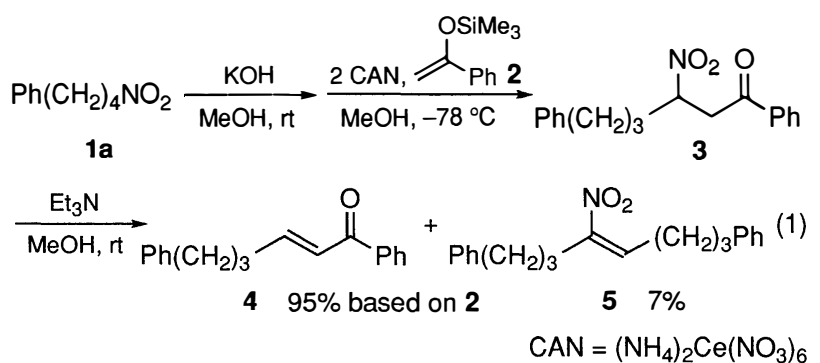

Even when the reaction was carried out by using exactly stoichiometric amounts of the reagents $(\mathbf{1 a}: \mathrm{KOH}: \mathrm{CAN}: \mathbf{2}=1$ : $1: 2: 1$ ), the addition product 4 was obtained in $85 \%$ yield with the recovery of $13 \%$ of $\mathbf{1 a}$; the self-coupling product 5 was not detected. It is well known that nitronate anions react with carbon electrophiles, such as alkyl halides, on the oxygen atom predominantly and selective $C$-alkylation is difficult. ${ }^{13}, 14$ In the present radical reaction with the silyl enol ether, exclusive $C$ alkylation was observed as shown in Eq. 1 .

The probable mechanism of the reaction is shown in Scheme 1. The nitronate anion $\mathbf{A}$ is oxidized to the $\alpha$-nitroalkyl radical $\mathbf{B}$, which adds to the enol ether. Successive oxidation of the radical intermediate $\mathbf{C}$ and desilylation afford the product, $\beta$ nitroketone.

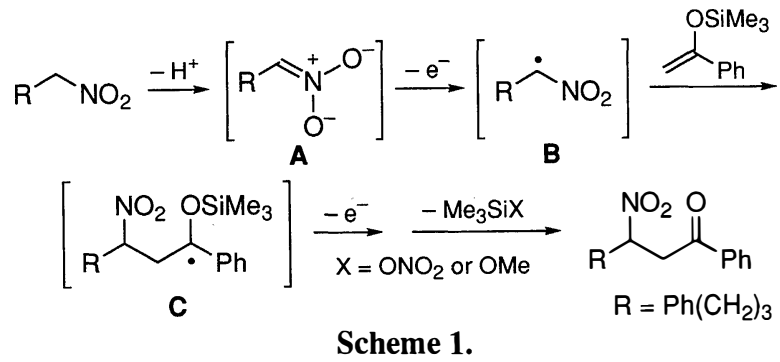

Use of other metallic oxidizing agents did not improve the yield of the product. The addition product 4 was obtained in $12 \%$ yield only when ferrocenium hexafluoro-phosphate was employed, and the use of $\mathrm{Fe}\left(\mathrm{NO}_{3}\right)_{3} \cdot 9 \mathrm{H}_{2} \mathrm{O}, \mathrm{Mn}(\mathrm{pic})_{3}$, or $\mathrm{Ag}$ (pic) 2 (pic = 2-pyridinecarboxylato) gave only the selfcoupling product $\mathbf{5}$, or brought about oxidation or hydrolysis of the silyl enol ether 2. As for the base used for generating the nitronate, alkali metal hydroxides $\left(\mathrm{LiOH} \cdot \mathrm{H}_{2} \mathrm{O}, \mathrm{NaOH}\right)$ and methoxides ( $\mathrm{NaOMe}, \mathrm{KOMe}$ ) could be employed successfully, however, no reaction occurred by the use of triethylamine.

The reactions between various nitroalkanes and silyl enol ethers were examined and the results are summarized in Table 1. The nitroalkane 1a reacted with several silyl enol ethers as well as the aryl silyl enol ether $\mathbf{2}$ to afford the corresponding addition products in high yield (Entries 1-3). When 5-nitropentyl acetate (1b) was employed, the addition products were obtained in moderate yield (Entries 4-6). A nitroalkane possessing two substituents at $\alpha$-position 1c and a cyclic nitroalkane 1d also afforded $\alpha, \beta$-unsaturated ketones in excellent yield in the reaction with 2 (Entries 7 and 9), however, the reactions with an aliphatic silyl enol ether resulted in poor yield (Entries 8 and 10). Phenylnitromethane (1e) gave a complex mixture and low yield of the product (Entry 11). In the case of nitromethane (1f), the oxidation did not proceed (Entry 12). 15 The configulation of the $\alpha, \beta$-unsaturated ketones obtained by these reactions was exclusively $E$.

Besides silyl enol ethers, vinyl ethers and styrene derivatives were available for the reaction. For instance, $\alpha$-methoxystyrene (6) reacted with the nitroalkane 1a, giving a dimethylacetal of $\beta$ nitroketone 7 in high yield (Eq. 2). 
Table 1. The oxidative cross-coupling reaction between nitroalkanes and silyl enol ethers ${ }^{\mathrm{a}}$

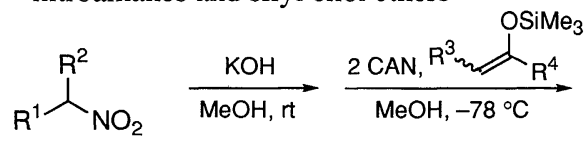

1a $\mathrm{R}^{1}=\mathrm{Ph}\left(\mathrm{CH}_{2}\right)_{3}, \mathrm{R}^{2}=\mathrm{H}$

1b $\mathrm{R}^{1}=\mathrm{AcO}\left(\mathrm{CH}_{2}\right)_{4}, \mathrm{R}^{2}=\mathrm{H}$

1c $\mathrm{R}^{1}, \mathrm{R}^{2}=\mathrm{Me}$

1d $\mathrm{R}^{1}, \mathrm{R}^{2}=\left(\mathrm{CH}_{2}\right)_{5}$

1e $R^{1}=P h, R^{2}=H$

1f $\mathrm{R}^{1}, \mathrm{R}^{2}=\mathrm{H}$

\begin{tabular}{ccccc}
\hline Entry & Nitroalkane & $\mathrm{R}^{3}$ & $\mathrm{R}^{4}$ & Yield /\% \\
\hline 1 & 1a & $\mathrm{H}$ & $\mathrm{Ph}$ & 95 \\
2 & 1a & $\mathrm{H}$ & $n$-Pr & 81 \\
3 & 1a & $\mathrm{Me}^{\mathrm{c}}$ & $\mathrm{Ph}$ & 79 \\
4 & 1b & $\mathrm{H}$ & $\mathrm{Ph}$ & $69^{\mathrm{d}}$ \\
5 & 1b & $\mathrm{H}$ & $n$-Pr & $60^{\mathrm{d}}$ \\
6 & 1b & $\mathrm{Me}^{\mathrm{c}}$ & $\mathrm{Ph}$ & $65^{\mathrm{d}}$ \\
7 & 1c & $\mathrm{H}$ & $\mathrm{Ph}$ & $98^{\mathrm{d}}$ \\
8 & 1c & $\mathrm{H}$ & $\mathrm{Ph}\left(\mathrm{CH}_{2}\right)_{2}$ & $4^{\mathrm{d}}$ \\
9 & 1d & $\mathrm{H}$ & $\mathrm{Ph}$ & $90^{\mathrm{d}}$ \\
10 & 1d & $\mathrm{H}$ & $\mathrm{Ph}\left(\mathrm{CH}_{2}\right)_{2}$ & $43^{\mathrm{d}}$ \\
11 & 1e & $\mathrm{H}$ & $\mathrm{Ph}$ & $10^{2}$ \\
12 & 1f & $\mathrm{H}$ & $\mathrm{Ph}$ & 0 \\
\hline
\end{tabular}

${ }^{a}$ Reactions were carried out according to the procedure described in the text. ${ }^{\mathrm{b}}$ Based on the silyl enol ethers. ${ }^{\mathrm{c}} E / Z=5 / 95$ (determined by NMR).

${ }^{d}$ The crude nitroketone was treated with DBU in $\mathrm{CH}_{2} \mathrm{Cl}_{2}$ instead of triethylamine in methanol.

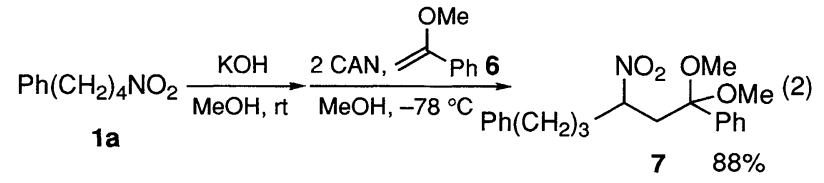

The reaction with $\alpha$-methylstyrene (8) afforded a methyl ether 9 (diastereomer mixture, 68:32) and a $\beta$-hydroxyketone 10, though 4 molar amounts of 8 were required (Eq. 3).

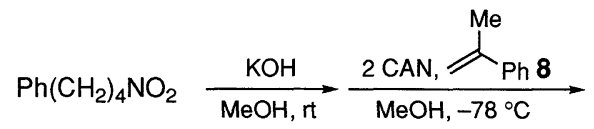

$$
\begin{aligned}
& 1 \mathrm{a} \\
& \mathrm{Ph}\left(\mathrm{CH}_{2}\right)_{3} \overbrace{\mathrm{Ph}}^{\mathrm{NO}_{2} \mathrm{OMe}}+{ }_{\mathrm{Ph}\left(\mathrm{CH}_{2}\right)_{3}}^{\mathrm{OMe}} \underbrace{\mathrm{O}}_{\mathrm{Ph}} \\
& 948 \% \text { based on } 1 \mathrm{a} \quad 1025 \% \text { based on } 1 \mathrm{a}
\end{aligned}
$$

The reaction can be applied for intramolecular cyclization. When nitro compounds $\mathbf{1 1 a}$ and $\mathbf{1 1 b}$ were treated with $\mathrm{KOH}$, followed by oxidation with CAN, the cyclized products 12a and 12b were obtained as a single stereoisomer in good yield, respectively (Eq. 4). The relative configuration of $\mathbf{1 2 b}$ was unambiguously determined as trans by $\mathrm{X}$-ray crystallographic analysis. 16

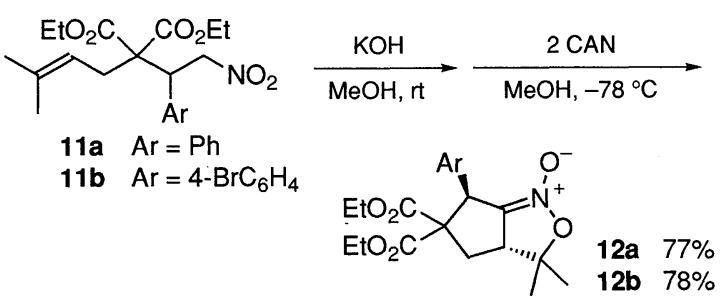

One of the authors (N. A.) is grateful to Fellowships of the Japan Society for the Promotion of Science for Japanese Junior Scientists. This work was partially supported by a Grant-in-Aid for Scientific Research from the Ministry of Education, Science and Culture.

\section{References and Notes}

1 H. J. Schäfer, Angew. Chem., Int. Ed. Engl., 20, 911 (1981).

2 J. L. Morgat and R. Palloud, C. R. Hebd. Seances Acad. Sci., 260, 574, 5579 (1965).

3 H. G. Thomas, M. Streukens, and R. Peek, Tetrahedron Lett., 1978, 45.

4 H. Schäfer and A. Al Azrak, Chem. Ber., 105, 2398 (1972).

5 H. Schäfer and H. Küntzel, Tetrahedron Lett., 1970, 3333.

6 Generation of carbon-centered radicals by indirect oxidation of alkyllithiums and their reactions with olefins were found in our laboratory: K. Narasaka and H. Sakurai, Chem. Lett., 1993, 1269.

7 K. Narasaka, N. Arai, and T. Okauchi, Bull. Chem. Soc. Jpn., 66, 2995 (1993).

8 K. Narasaka and Y. Kohno, Bull. Chem. Soc. Jpn., 66, 3456 (1993).

9 Y. Kohno and K. Narasaka, Bull. Chem. Soc. Jpn., 68, 322 (1995).

10 Several $\mathrm{C}-\mathrm{C}$ bond formations by oxidation of nitronates are known, however, their utility is rather restricted: Intramolecular; A. S. Kende and K. Koch, Tetrahedron Lett., 27, 6051 (1986); W. R. Bowman and S. W. Jackson, Tetrahedron Lett., 30, 1857. (1989); W. R. Bowman, D. S. Brown, C. A. Burns, and D. Crosby, J. Chem. Soc., Perkin Trans. 1, 1993, 2099. Intermolecular; M. E. Kurz and P. Ngoviwatchai, J. Org. Chem., 46, 4672 (1981); N. Kornblum, H. K. Singh, and W. J. Kelly, J. Org. Chem., 48, 332 (1983).

$11 \mathrm{C}-\mathrm{C}$ bond formations by oxidation of silyl esters of nitronates: K. Narasaka, K. Iwakura, and T. Okauchi, Chem. Lett., 1991, 423.

12 The use of small excess amounts of $\mathbf{1}$ vs. 2 is recommended, since unreacted 1 was recovered even if 1.8 molar amounts of 2 were employed.

13 D. Seebach and F. Lehr, Angew. Chem., Int. Ed. Engl., 15, 505 (1976).

14 M. V. Proštenik and I. Butula, Angew. Chem., Int. Ed. Engl., 21, 139 (1982).

15 Though self-coupling products such as $\mathbf{5}$ were obtained in Entries 1-3 and 11, in other cases the corresponding dimers were not detected.

16 Crystal data for $\mathbf{1 2 b}: \mathrm{C}_{20} \mathrm{H}_{24} \mathrm{BrNO}_{6}, M_{\mathrm{W}}=454.32$, colorless prism, monoclinic, $P 2{ }_{1} / a$ (\#14), $a=8.655(3), b=$ 19.595(4), $c=12.411(4) \AA, \beta=100.90(2)^{\circ}, V=2067.0(9)$ $\AA^{3}, Z=4, D_{\text {calc }}=1.460 \mathrm{~g} \mathrm{~cm}^{-3}, \mu(\mathrm{Mo} K \alpha)=20.30 \mathrm{~cm}^{-1}, R$ $=0.075, R_{\mathrm{W}}=0.050,3790$ unique reflections. 